\title{
Brucellosis in Ethiopia
}

\author{
Moti Yohannes ${ }^{1}$, Hailu Degefu' ${ }^{1}$, Tadele Tolosa ${ }^{1}$, Kelay Belihu ${ }^{2}$, Ronald Cutler ${ }^{3}$ and \\ Sally Cutler ${ }^{4 *}$
}

${ }^{1}$ School of Veterinary Medicine, College of Agriculture and Veterinary Medicine of Jimma University,

P. O. Box 307, Jimma, Ethiopia.

${ }^{2}$ FAO Ethiopia, P. O. Box 5536, Addis Ababa, Ethiopia.

${ }^{3}$ School of Biological and Chemical Sciences, Queen Mary University of London, London, United Kingdom.

${ }^{4}$ School of Health, Sport and Bioscience, University of East London, Water Lane, London, E15 4LZ, United Kingdom.

Accepted 15 February, 2013

\begin{abstract}
We reviewed the distribution of brucellosis in different regions of Ethiopia and its prevalence among different livestock hosts. In the absence of recent published documents, unpublished studies were cited to provide some information on distribution and importance of brucellosis in Ethiopia. Risk factors for the occurrence of brucellosis are also reviewed. Finally, different strategies for the control and prevention of brucellosis under Ethiopian conditions are discussed.
\end{abstract}

Key words: Brucellosis, control, distribution, Ethiopia host, risk factors, prevention.

\section{INTRODUCTION}

Brucellosis is a zoonotic disease that leads to considerable morbidity resulting in significant loss of working days across the globe and thus perpetuates poverty. The disease is presented as an acute or persistent febrile illness with a diversity of clinical manifestations (Smits and Kadri, 2004). Various synonyms have been used for human brucellosis including Malta fever, Rock fever of Gibraltar, Cyprus or Mediterranean fever, intermittent typhoid and most frequently, undulant fever (Al Dahouk et al., 2003).

The incubation period varies between 14 and 120 days (Seifert, 1996). Primary clinical manifestations of brucellosis among livestock are related to the reproductive tract. In highly susceptible non-vaccinated pregnant cattle, abortion after the $5^{\text {th }}$ month of pregnancy is cardinal feature of the disease (Radostits et al., 2000). Retention of placenta and metritis are common sequels to abortion (Walker, 1999). Females usually abort only once, presumably due to acquired immunity. In general, abortion with retention of the placenta and the resultant metritis may cause prolonged calving interval and permanent infertility. In humans, the disease is characterized by a multitude of somatic complaints, such as fever, sweating, anorexia, malaise, weight loss, depression, headache and joint pains and is easily confused with malaria and influenza (Sewell and Brocklesby, 1990; WHO, 1997).

The genus Brucella are Gram-negative, facultative, intracellular coccobacillary comprised of species based upon biochemical features and their correlation with preferred host species (OIE, 2000). This has been an area of controversy, with species status being revoked on the basis of 16S rRNA gene sequencing, however subsequently, this decision was revoked (Osterman and Moriyon, 2006). Currently ten species are recognized including the better known six classical species comprised of $B$. abortus (cattle, biovars 1-6, and 9), $B$. melitensis (goats, sheep, biovars 1-3), B. suis (pigs, reindeer and hares, biovars 1-5), B. ovis (sheep), $B$. canis (dogs) and $B$. neotomae (desert wood rats). More recently, new members to the genus include $B$. ceti and B. pinnipedialis (dolphins/porpoises and seals respectively), $B$. microti (voles) and $B$. inopinata (reservoir undetermined) (Godfroid et al. 2011). 
Of these species, $B$. melitensis has the greatest risk for human infection followed by $B$. suis and $B$. abortus, however several of the other species have been shown to be virulent for humans (Godfroid et al. 2011).

Bovine brucellosis is usually caused by Brucella abortus, less frequently by $B$. melitensis, and rarely by $B$. suis, Although Brucella abortus is mainly associated with cattle, occasionally other species of animals such as sheep, swine, dogs and horses may be infected. In horses, B. abortus together with Actinomyces bovis may be present in poll evil and fistulous withers (Roberts, 1971; Radostits et al., 2000).

The disease occurs worldwide, except in those countries where bovine brucellosis ( $B$. abortus) has been eradicated. The disease remains endemic among Mediterranean countries of Europe, Northern and Eastern Africa, Near East countries, India, Central Asia, Mexico and Central and South America. Although B. melitensis has never been detected in some countries, there are no reliable reports that it has ever been eradicated from small ruminants (FAO, 2003). Furthermore, brucellosis is also considered as a re-emerging problem in many countries such as Israel, Kuwait, Saudi Arabia, Brazil and Colombia, where there is an increasing incidence of $B$. melitensis or $B$. suis biovar 1 infection in cattle (Cutler et al., 2005).

Ethiopia, located in Eastern Africa, is predominantly an agrarian country with over $85 \%$ of its population engaged in agricultural activity. The country has diverse agroecological zones, which have contributed to the evolution of different agricultural production systems. Animal husbandry forms an integral part of agricultural production in almost all ecological zones of the country (Tegenge and Crawford, 2000). Brucellosis prevalence studies have been conducted in different localities of the country. Even then, there is little information on specific transmission dynamics within Ethiopia. To our knowledge, the first published cases of the disease date back to 1970s (Domenech and Lefever, 1974; Domenech, 1977). These papers review presumptive brucellosis in Ethiopia and approaches for its control and prevention.

\section{EPIDEMIOLOGY OF THE DISEASE}

\section{Hosts and species of Brucella}

In Ethiopia, brucellosis in animals and humans has been reported from different localities of the country, particularly associated with cattle in both intensive and extensive management systems (Domenech, 1977; Richard, 1979; Assegid, 1987; Molla, 1989; Belihu, 2002). These prevalence studies in animals and human were largely confined to serological surveys and commonly targeted bovine brucellosis, occasionally sheep and goats and rarely camels. So far, attempts to identify Brucella species in the country were unsuccessful; the distribution and proportion of their natural hosts was also not studied exhaustively. This is largely attributed to the degree of laboratory development and lack of consumables for laboratory tests.

\section{BRUCELLOSIS IN LIVESTOCK}

\section{Bovine brucellosis}

The most significant economic losses are usually incurred following bovine brucellosis. For instance, the serological prevalence of bovine brucellosis in Central America during the last 10 years has been estimated as between 4 and $8 \%$, with higher prevalence in dairy herds and with losses calculated at US\$25 million per year (Moreno, 2002). In Ethiopia, information on losses specifically through brucellosis in the different types of production systems is sparse, with the exception of Tariku (1994) who reported an annual loss from brucellosis estimated to be 88,941.96 Ethiopian Birr (\$5231 equivalent) among 193 cattle, largely due to reduced milk production and abortions (Chaffa State Farm, Wollo, from 1987 to 1993).

Both husbandry systems as well as environmental conditions greatly influence the spread of Brucella infection (WHO, 1986). Ethiopia has several institutionally owned commercial dairy farms, mostly situated in and around Addis Ababa and in some regional towns. These farms have been the focus of most Brucella surveys, potentially producing a bias in reported findings. These prevalence reports have been systematically reviewed as intensive and extensive management systems of various regions in Ethiopia.

\section{Prevalence in intensive management system}

Higher individual bovine brucellosis seroprevalence has been recorded in intensively managed cattle herds as compared to those in the extensive management system. In Borena Zone of Oromia Region, the highest seroprevalence $(50 \%)$ was documented using ELISA in Didituyura Ranch (Alem and Solomon, 2002). A seroprevalence of $39 \%$ was also recorded at the Institute of Agricultural Research in Western Ethiopia (Meyer, 1980), 22\% in Dairy Farm in Northeastern Ethiopia (Tariku, 1994), 11 to $15 \%$ in dairy farms and ranches in Southeastern Ethiopia (Bekele et al., 2000), 8.2\% in Arsi area (Molla, 1989), $8.1 \%$ in dairy farms in and around Addis Ababa (Asfaw et al., 1998), and $7.7 \%$ in Tigray region (Haileselassie et al., 2010). On a cautionary note, different serodiagnostic methods might cause some variability. Similarly, some question the value of testing individual animals, instead preferring to class infection at the herd level rather than the individual animal. 
Relatively low individual animal seroprevalence were recorded in some intensive farms in different parts of the country. Kassahun et al. (2007) documented $2.46 \%$ in Sidama Zone of Southern Ethiopia, Mussie et al. (2007a) reported a prevalence of $4.63 \%$ in Northwestern part of Amhara Regional State. According to these authors, the reasons for the low prevalence of bovine brucellosis in these study areas were explained by better hygienic practices, use of maternity pen and/or separation of cows during parturition, cleaning and disinfection activities, culling of infected animals, depending on own herds for replacing stock and farm owners knowledge of brucellosis in these intensive farms.

In contrast to the above reports, Alem and Solomon (2002) and Belihu (2002) failed to find any seroreactive cattle after screening 564 animals in Eastern and Western Showa zones of central Ethiopia using rosebengal plate test (RBPT), serum agglutination test (SAT) and complement fixation test (CFT). Similarly, Belihu (2002) could not find positive reactors in intensive dairy farms in Addis Ababa area $(n=747)$.

\section{Prevalence in extensive management system}

In Ethiopia, 95\% of cattle are farmed under extensive systems. According to the available data, Brucella seroprevalence within extensive cattle rearing systems is lower than that of intensive systems. Tolosa et al. (2008) reported overall individual animal prevalence and herd prevalence of 0.77 and $2.9 \%$, respectively in Jimma Zone. Recent reports from North West, Tigray region (Haileselassie et al., 2010) and Southern Sidama Zone (Asmare et al., 2010), recorded an overall prevalence of 1.2 and $1.66 \%$ following screening 848 and 1627 cattle from extensive system, respectively.

A cross-sectional epidemiological study carried out in Tigray Region of Ethiopia revealed that of 816 indigenous cattle sera examined, only $27(3.3 \%)$ were seropositive using RBPT, of which 26 (3.19\%) were also positive by CFT. Overall herd-level prevalence was reported to be $42.31 \%$ and the within-herd prevalence varied from 0 to $15.15 \%$ based on CFT (Berhe et al., 2007). In another study, Ibrahim et al. (2010) reported overall individual and herd level seroprevalences of 3.1 and $15.0 \%$, respectively. Using CFT, Kebede et al. (2008) reported individual and herd animal prevalence of 11.0 and $45.9 \%$, respectively. Dinka and Chala (2009) investigated bovine brucellosis using RBPT in four districts of East Showa Zone. In their study, Brucella antibody was detected in 8.7, 18.6, 5.1 and $10 \%$ of the samples in Fentale, Arsi Negele, Lume and Adami Tulu study districts, respectively. The overall herd prevalence was reported to be $11.2 \%$. Jergefa et al. (2009) also conducted seroprevalence study using RBPT and CFT in three agroecological areas of central Oromiya namely: Walmara, Adami Tulu-Jido Kombolcha and Lume Districts. Their result revealed overall prevalence of 2.9 and $13.6 \%$ in individual animal and herd level, respectively.

\section{Ovine and caprine brucellosis}

There is paucity of published data on the status of small ruminant brucellosis in Ethiopia. Among few reports, Teshale et al. (2006) tested sera from 2000 sheep and goats in pastoral regions of Ethiopia and documented $1.9 \%(n=38)$ positive using RBPT and 9.7\% $(n=193)$ positive by i-ELISA. Another cross-sectional study conducted on 1,568 serum samples from sheep and goats in the pastoral region of Afar revealed $9.4 \%$ positive using RBPT and $4.8 \%$ positive by CFT (Ashenafi et al., 2007). In Jijiga, Mohammed (2009) screened 730 serum samples (430 sheep and 300 goats) and the result revealed 1.64 and $1.51 \%$ positivity using RBPT and CFT, respectively. Additionally, Tekelye and Kasali (1990) reported prevalence proportion of $1.5 \%$ in sheep and $1.3 \%$ in goats in central highland. Yibeltal (2005) documented prevalence of $15 \%$ in sheep and $16 \%$ in goats in Afar region. Mengistu (2007) examined a total of 3964 small ruminants (2905 sheep and 1059 goats) in Southern Ethiopia and reported an overall seroprevalence of $1.6 \%$ in sheep and $3.2 \%$ in goats after serial testing using RBPT and CFT. Shimeles (2008) tested a total of 2409 sheep in the eastern part of Amhara Region and found out a seroprevalence of $4.89 \%$ after serial testing using RBPT and CFT.

\section{Camel brucellosis}

Camel brucellosis in Ethiopia is largely understudied. Initial data published on camel brucellosis (Domenech, 1977 ) in the provinces of Sidamo, Harar and Tigray reported seroprevalence of $4.4 \%(n=977)$. In addition, Teshome et al. (2003) investigated seroprevalence of brucellosis in 1442 camels in arid and semi-arid camelrearing regions (Afar, Somali and Borena) of Ethiopia. Their study showed $5.7 \%$ seropositive with RBPT and $4.2 \%$ using CFT. In Borena lowland, Megersa et al. (2005) investigated camel brucellosis using RBPT and CFT. In their study Brucella antibodies were detected in $1.8 \%(58 / 3218)$ of camels tested. Birhanu (2006) reported an individual animal and herd seroprevalence of $2.43 \% \quad(n=822)$ and $10.3 \% \quad(n=185)$ in camels in southeast lowland areas of the Somale Region.

\section{Other animals}

Dogs are popular domestic pets in Ethiopia. Although the population of dogs in the country is unknown, estimates suggest that both rural and urban communities possess at least one dog per family. Furthermore, in the urban 
areas, it is not uncommon to find a large number of stray dogs roaming freely in the streets scavenging for their survival. In dairy farms, dogs are commonly fed with raw milk and carcasses, including aborted fetuses and retained fetal membranes. Despite these risk factors that might serve as sources of infection among dogs, canine brucellosis has not been studied in the country.

The importance of brucellosis in equine, swine and wild animals has also not been addressed to date. Since human and animal interactions occur in various ways, the study of brucellosis in companion animals in Ethiopia is currently a knowledge gap that should be addressed.

\section{Human brucellosis in Ethiopia}

Brucellosis primarily affects livestock, but can be transmitted to humans by ingestion, close contact, inhalation or accidental inoculation. The prevalence of human brucellosis differs between areas and has been reported to vary with standards of personal and environmental hygiene, animal husbandry practices, species of the causative agent and local methods of food processing (Chugh, 2008).

The Brucellosis 2003 International Research Conference estimated that 500,000 human infections occur per year worldwide, with incidences ranging from less than one case per 100,000 population in UK, USA and Australia, through 20 to 30 cases per 100,000 in southern European countries such as Greece and Spain, to more than 70 cases per 100,000 in Middle Eastern States such as Kuwait and Saudi Arabia (Cutler and Whatmore, 2003; Pappas et al., 2006).

As compared to study of animal brucellosis, study of human brucellosis in Ethiopia is sparse with even less information on risk factors for human infection. For instance, out of 56 cases with fever of unknown origin, two $(3.6 \%)$ were reported to be positive for $B$. abortus antibodies by RBPT and CFT (Tolosa et al., 2007). A study conducted in traditional pastoral communities by Ragassa et al. (2009) using B. abortus antigen revealed that $34.1 \%$ patients with febrile illness from Borena, $29.4 \%$ patients from Hammer and $3 \%$ patients from Metema areas were tested positive using Brucella IgM/lgG Lateral Flow Assay. But they failed to include a parallel study of animal brucellosis. Studies conducted in high risk group such as farmers, veterinary professionals, meat inspectors and artificial insemination technicians in Amhara Regional State (Mussie et al., 2007b), Sidama Zone of Southern People Nations and Nationalities Sate (Kasahun et al., 2007) and Addis Ababa (Kassahun et al., 2006) found a seroprevalence of $5.30 \%, 3.78 \%$ and $4.8 \%$ by screening sera from 238, 38 and 336 individuals respectively. The discrepancy between Regassa et al. (2009) and others might be due to difference in milk consumption habits and sensitivity of test methods used. Furthermore, Abebe et al. (2009) assessed the prevalence of major causative agents of acute febrile illness in 653 outpatients of four health centers in Northern Ethiopia. Among these febrile patients, $B$. abortus was detected in $6.3 \%, 3 \%$ and none of the patients in Finoteselam, Quarit, and both Dembecha and Jiga, respectively. It must be remembered that as these investigations were of acute cases and as such, they may not have had sufficient time to allow seroconversion. Similarly, seroreactivity may not correlate with the acute febrile episode for which the individuals were admitted.

\section{Risk factors influencing the occurrence of animal brucellosis}

Cattle susceptibility to $B$. abortus infection is influenced by age, sex, breed and reproductive status of the individual animal (Radostits et al., 2000). The association of these factors with the infection has also been studied in different parts of Ethiopia. In Borena lowland, the effect of gender was observed to be significant for seroprevalence by Megersa et al. (2005). According to Mussie et al. (2007a) gender of cattle showed significant influence $(\mathrm{p}=0.042)$ on seroprevalence, with more females $(5.97 \%)$ seropositive than males $(0.92 \%)$ in the semi-intensive production system. Higher numbers of female reactors were also reported in ranch and extensive production systems. The same result was been observed in a study done at Addis Ababa dairy farms by Asfaw et al. (1998), where they found a higher proportion of females $(8 \%)$ infected than males $(0.11 \%)$, though the difference was not significant. Tolosa et al. (2008) has also reported higher proportion of female reactors than males in both extensive and intensive production systems, though the difference was yet again not significant. The study of Kassahun et al. (2007) in cattle revealed $2.49 \%$ female reactors whereas none of the bulls were found to test positive within the intensive management systems. On the other hand, the results in extensive production system in the same study showed quiet the opposite in that the proportion of reactor males $(4 \%)$ outweighed that of the females (1.62\%). Dinka and Chala (2009) reported a prevalence among cattle of $12.2 \%$ in females and $9.8 \%$ in males however failing to reach statistical significance.

Age is also one of risk factors reported by different researchers. For instance, Kassahun et al. (2007) reported that the majority $(97.87 \%)$ of seroreactors detected were in animals above 2 years of age in both the extensive and intensive management systems. In Jimma, Tolosa et al. (2008) reported significant variation among age groups in extensive production systems with almost zero cases in the age group of $0.5-3$ years, $1.1 \%$ in the age group of more than $3-6$ years and $1.6 \%$ in the age group above 6 years. In another study older cattle were twice more likely to be affected by brucellosis than younger ones (Asfaw et al., 1998). Moreover, the 
investigation of Mussie et al. (2007a) in Amhara Regional State documented a statistically significant variation $(p$ $<0.05$ ) among the three age groups of 0.5 - 1 year $(2.70 \%),>1-3$ years $(4.22 \%)$ and $>3$ years $(4.23 \%)$. Dinka and Chala (2009) also observed 12.0\% seroprevalence within older animals ( $>2$ years) whereas $10.2 \%$ in younger animals (2 years) but failed to show statistically significance.

Herd size is another risk factor that affects occurrence of brucellosis. In Amhara region Mussie et al. (2007a) observed significant differences of Brucella seroprevalences $(p<0.05)$ among three herd size categories in the semi-intensive production system whereas the difference was not statistically significant in the extensive production system. Their findings revealed comparatively higher seropositivity in the larger herd categories $(5-10$ and $>10)$ than those herds with less than 5 cattle. A separate study in Addis Ababa area by Asfaw et al. (1998) also found significant association between Brucella infection and herd size. Kassahun et al. (2007) also reported that in both extensive and intensive systems, infection rates increased with herd size, but these differences failed to achieve statistical significance. On the other hand, Tolosa et al. (2008) reported highly significant variation $(p<0.001)$ between herds having 1 to 5 cattle and those with $>5$ cattle.

Few comparative studies have been under taken to show the status of bovine brucellosis in different agroclimatic areas of this country. For example, Mussie et al. (2007a) reported higher seroprevalence in the midland areas (with individual rates of $5.61 \%$ compared with $22.4 \%$ at herd level), than highland areas (with individual rates of $1.97 \%$ and $6.33 \%$ at herd level respectively) within the Amhara Regional State. A possible explanation could be a consequence if higher stocking density in the midland area compared with the highland regions. Similar findings were also reported by Fekadu (1999) in the northeastern areas of Amhara Region where $0.2 \%$ prevalence was detected in the highland and $3 \%$ in lowland areas. Additionally, Tekleye et al. (1989) reported almost equivalent sero-prevalence in different agroclimatic areas of Oromia Region namely Gibe, which represent the lowland (4.3\%) and Gobe, representing highland $(4.1 \%)$. In central Oromiya, Jergefa et al. (2009) documented seroprevalence of $17 \%$ in lowlands, $5.1 \%$ in midlands and 18.6 in highland areas.

\section{SUGGESTED PREVENTION AND CONTROL STRATEGIES FOR LIVESTOCK BRUCELLOSIS IN ETHIOPIA}

As the source of human brucellosis is direct or indirect exposure to infected animals or their products, prevention must focus on various strategies that will mitigate infection risks. To our knowledge, there has been no national programme proposed for prevention and control of brucellosis in Ethiopia. Similarly at regional levels, no strategy is in place to control brucellosis. This is largely a result of lack of facilities and budget to run such a program. Moreover, many responsible bodies may not recognize the significance of brucellosis given the contradictory and sometimes low prevalence data. However, at this time, it is crucial to define geographical extent of the problem and then allocate resources and funds to initiate prevention and control strategies in this country. These strategies have been proposed as follows.

\section{Defining geographical extent and magnitude of brucellosis}

\section{Classification of endemic areas based on prevalence}

This will enable instigation of appropriate control method in endemic areas. Identification of low and high prevalence areas will greatly facilitate the implementation of appropriate control programmes, and should ideally be combined with other strategies like accurate livestock census data and a livestock identification system (either simple ear notches or more sophisticated ear labelling system). Vaccine storage and quality control systems are also a priority coupled with surveillance systems and post-vaccination surveillance to identify the remaining foci of infection (the efficacy of post-vaccination surveillance is reliant upon existing records combined with reliable livestock identification). In areas where the disease is less prevalent (for example livestock seroprevalence of less than 1\%), we may recommend test and cull policy with compensation. For areas with high and moderate prevalence $(>5 \%)$ under well-organized farming systems, we may recommend test and segregation policy by which animals with brucellosis will be isolated and products consumed after pasteurization, with animals being disposed of properly at the end of their productive live.

\section{Characterization of Brucella species}

One of the most successful methods for prevention and control of livestock brucellosis is through vaccination. In different parts of the world both live vaccines, such as $B$. abortus S-19, $B$. melitensis Rev-1, B. suis S-2, rough $B$. melitensis strain M111 and $B$. abortus strain RB51 and killed vaccines, such as $B$. abortus $45 / 20$ and $B$. melitensis $\mathrm{H} .38$ are available. Each vaccine has been reported to have its own advantages and disadvantages (Thakur and Thapliyal, 2002), with protection following localized persistence of live vaccines preferred by most and showing efficacy in small ruminants (Smits, 2012; Ward et al., 2012) and cattle (Cheville et al., 1996). Use of the RB51 attenuated live vaccine has recently gained popularity for control of brucellosis in cattle (Cheville et al., 1996), but on a cautionary note, the failure of this 
strain to induce serological reactivity, coupled with its inherent resistance to rifampicin, might complicate detection and management of zoonotic infection spilling into humans with occupational risk factors for acquiring brucellosis. Currently, despite huge research efforts, no vaccine has been approved for the prevention of human brucellosis. Treatment regimes for human brucellosis require combination of antibiotics. These have recently been compared using meta-analysis (Skalsky et al., 2008). Currently, vaccination against animal brucellosis has yet to be explored in Ethiopia. As a prerequisite, Brucella species identification should be undertaken to inform selection of the most appropriate vaccine, for example, B. melitensis has recently been found infecting cattle in Kenya (Muendo et al., 2012) and to enable differentiation of vaccine and wild-type strains.

Vaccination is generally recommended for seroprevalence rates between 2 and $10 \%$. Whether a strategy of test and segregation alone for high seroprevalence rates is sufficient may depend on the farming conditions. This might be appropriate for farms in conjunction with appropriate hygienic measures, but supplementation with vaccination may be required to control the disease in extensive livestock conditions.

\section{Application of farm biosafety measures}

Implementation of measures to reduce the risk of infection through personal hygiene, adoption of safe working practices, protection of the environment and food hygiene should minimize risks of further infection.

Under appropriate conditions, Brucella organisms can survive in the environment for prolonged periods. Their ability to withstand inactivation under natural conditions is relatively high compared with most other groups of nonsporing pathogenic bacteria (WHO, 1986). B. abortus is inactivated by pasteurization and its survival outside the host is largely dependent on environmental conditions. The pathogen may survive in aborted fetus in the shade for up to eight months, for two to three months in wet soil, one to two months in dry soil, three to four months in faeces, and eight months in liquid manure tanks (Bishop et al., 1994; Walker, 1999). For example, in nomadic populations where people travel in search of green pasture and water, the proper handling and burying of abortion materials to prevent contamination of water sources and pasture is of paramount importance. Furthermore, the common practice of feeding abortion materials to dogs should be avoided as this increases the risk of transmission to other animals. It is imperative to education on risks for infection to these populations in order to influence behavioral practices that will reduce risks of transmission.

Bacterial survival is prolonged at low temperatures and organisms will remain viable for many years in frozen carcases. Brucellae in aqueous suspensions are readily killed by most disinfectants. A $10 \mathrm{~g} / \mathrm{l}$ solution of phenol will kill brucellae in water after less than 15 min exposure at $37^{\circ} \mathrm{C}$. Formaldehyde solution is the most effective of the commonly available disinfectants, provided that the ambient temperature is above $15^{\circ} \mathrm{C}(\mathrm{WHO}, 1986)$.

\section{Application of veterinary extension}

The development of a national veterinary extension services in the country, is essential to promote awareness about brucellosis, its impact on livestock production and zoonotic risks, would provide a valuable prevention measure. This would help to unify both community/dairy cattle producers to control and eliminate brucellosis. Currently, many dairy cattle producers hide or dispose of animals with a history of abortion, potentially facilitating disease transmission between farms and regions. This seriously undermines efforts of controlling and preventing the disease.

\section{CONCLUSIONS}

The existing scenario of brucellosis in Ethiopia calls for urgent capacity building of regional laboratories. Coordinated nationwide epidemiological surveillance is urgently required together with typing of infecting strains, thus enabling the transmission dynamics to be elucidated and informing upon control and eradication strategies. Since animal reservoirs are the ultimate source of infection for humans, a holistic approach in control/eradication program should be maintained to reduce the impact of the disease on human health and the livestock economy. For both human and animal brucellosis, extension services should include emphasis on addressing the impacts of risk factors for the occurrence of brucellosis. Furthermore, interdisciplinary collaboration and joint ventures among medical, veterinary and public health professionals is of paramount importance to control this disease that currently perpetuates poverty.

\section{REFERENCES}

Abebe A, Yalemtsehay M, Damte S, Eden E (2009). Febrile illnesses of different etiology among outpatients in four health centers in northwestern Ethiopia. Jpn. J. Infect. Dis. 62:107-110.

Alem W, Solomon G (2002). A retrospective sero-epidemiology study of Bovine Brucellosis in different Production Systems in Ethiopia .In: Proceeding of $16^{\text {th }}$ Annual Conference. pp 53-57. June 5-6, Addis Ababa, Ethiopia.

Al Dahouk S, Tomaso H, Nockler K, Neubauer H, Frangoulidis D (2003). Laboratory-based diagnosis of brucellosis-a review of the literature. Part II: serological tests for brucellosis. Clin. Lab. 49:577589.

Asfaw $Y$ (1998). The epidemiology of brucellosis in intra and peri urban dairy production system in and around Addis Ababa. MSc thesis, Faculty of Veterinary Medicine, Addis Ababa University, Debre Zeit, Ethiopia. 
Ashenafi F, Teshale S, Ejeta G, Fikru R, Laikemariam Y (2007). Distribution of brucellosis among small ruminants in the pastoral region of Afar, eastern Ethiopia. Rev. Sci. Technol. 26:731-739.

Asmare K, Asfaw Y. Gelaye E, Ayelet G (2010). Brucellosis in extensive management system of Zebu cattle in Sidama Zone, Southern Ethiopia. Afr. J. Agric. Res. 5:257-263.

Assegid S (1987). The prevalence of bovine brucellosis under different management systems around Shoa region based on serological tests. DVM thesis, Faculty of Veterinary Medicine, Addis Ababa University, Debre Zeit, Ethiopia.

Bekele A, Molla B, Asfaw Y, Yirgu L (2000). Bovine brucellosis, seroepidemiological study in selected farms and ranches in South Eastern Ethiopia. Bull. Anim. Health Prod. Afr. 48:13-17.

Belihu K (2002). Analysis of dairy cattle breeding practices in selected areas of Ethiopia. PhD Thesis, Humboldt University, Berlin.

Berhe G, Belihu K, Asfaw Y (2007). Seroepidemiological investigation of bovine brucellosis in the extensive cattle production system of Tigray region of Ethiopia. Int. J. Appl. Res. Vet. Med. 5:65-71.

Birhanu T (2006). Camel management and status of camel brucellosis in Jijiga zone, southeast lowland areas in Somali national regional state, eastern Ethiopia. MSc Thesis, Faculty of Veterinary Medicine, Addis Ababa University, Debre Zeit, Ethiopia.

Bishop GC, Bosman PP, Herr S (1994). Bovine Brucellosis. In: Coetzer, Thomson and Tustin (eds.): Infectious Diseases of Livestock. Vol. 2. Cape Town, RSA: Oxford University Press, pp. 1053-1066.

Chugh TD (2008). Emerging and re-emerging bacterial diseases in India. J. Biosci. 33:549-555.

Cheville NF, Olsen SC, Jensen AE, Stevens MG, Palmer MV, Florance AM (1996). Effects of age at vaccination on efficacy of Brucella abortus strain RB51 to protect cattle against brucellosis. Am. J. Vet. Res. 57:1153-1156.

Cutler S, Whatmore A (2003). Progress in understanding brucellosis. Vet. Rec. 153:641-642.

Cutler SJ, Whatmore AM, Commander NJ (2005). Brucellosis - new aspects of an old disease. J. Appl. Microbiol. 98:1270-1281.

Dinka H, Chala R (2009). Seroprevalence Study of Bovine Brucellosis in Pastoral and Agro-Pastoral Areas of East Showa Zone, Oromia Regional State, Ethiopia. Am. Eurasian J. Agric. Environ. Sci. 6:508512.

Domenech J (1977). Brucellose de dromadaire en Ethiopie. Revue de' Elevage et Medicine Veterinaire des Pays Tropicaux 30:141-142.

Domenech J, Lefevre PC (1974). Serological survey on contagious bovine pleuropneumonia and bovine brucellosis in Ethiopia. Revue d'Elevage et de Medecine Veterinaire des Pays Tropicaux 27:397402.

FAO (2003). Guidelines for coordinated human and animal brucellosis surveillance. FAO Animal Production and Health Paper 156, Rome, Italy. pp. 1-45.

Fekadu K (1999): An epidemiological survey of bovine brucellosis in Amhara National Regional State. In: proceeding of the $14^{\text {th }}$ Annual Conference of Ethiopian Veterinary Association, June 8-9, Addis Ababa, Ethiopia.

Godfroid J, Scholz HC, Barbier T, et al. (2011) Brucellosis at the animal/ecosystem/human interface at the beginning of the 21 st century. Prev. Vet. Med. 102:118-131.

Haileselassie M, Shewit K, Moses K (2010). Serological survey of bovine brucellosis in barka and arado breeds (Bos indicus) of Western Tigray, Ethiopia. Prev. Vet. Med. 94(1-2):28-35.

Ibrahim N, Belihu K, Lobago F, Bekana M (2010). Sero-prevalence of bovine brucellosis and its risk factors in Jimma zone of Oromia Region, South-western Ethiopia. Trop. Anim. Health Prod. 42:35-40.

Jergefa T, Kelay B, Bekana M, Teshale S, Gustafson H, Kindahl H (2009). Epidemiological study of bovine brucellosis in three agroecological areas of central Oromiya, Ethiopia. Rev. Sci Tech Off. Int. Epiz. 28:933-943.

Kassahun A, Shiv P, Yilkal A, Esayas G, Gelagaye A, Aschalew Z (2007). Seroprevalence of brucellosis in cattle and high risk professionals in Sidama Zone, Southern Ethiopia. Ethiop. Vet. J. 11:69-84.

Kassahun J, Yimer E, Geyid A, Abebe P, Newayeselassie B, Zewdie B, Beyene M, Bekele A (2006). Sero-prevalence of brucellosis in occupationally exposed people in Addis Ababa, Ethiopia. Ethiop.
Med. J. 44:245-252.

Kebede T, Ejeta G, Ameni G (2008). Seroprevalence of bovine brucellosis in smallholder farms in central Ethiopia (Wuchale-Jida district). Revue. Méd. Vét. 159:3-9.

Megersa B, Molla B, Yigezu L (2005). Seroprevalence of brucellosis in camels (Camelus dromedarius) in Borena Lowland, southern Ethiopia. Bull. Anim. Health Prod. Afr. 53:252-257.

Mengistu M (2007). Seroepidemiology of Brucellosis in Small Ruminants in Southern Ethiopia. MSc thesis, Addis Ababa University, Faculty of Veterinary Medicine, Debre Zeit, Ethiopia.

Meyer CE (1980). Report on veterinary activities. Institute of Agricultural Research, Ethiopia. FAO Report No. AG: DP/ETH/78/004. FAO (Food and Agriculture Organization of the United Nations), Rome, Italy. p. 24.

Mohammed H (2009). Seroprevalence of small ruminant brucellosis in and around Jijiga. DVM thesis, School of Veterinary Medicine, Jimma University, Jimma, Ethiopia.

Molla B (1989). Seroepidemiological survey of bovine brucellosis in Arssi Region. DVM thesis, Faculty of Veterinary Medicine, Addis Ababa University, Debre Zeit, Ethiopia.

Moreno E (2002). Brucellosis in Central America. Vet. Microbiol. 90:3138.

Muendo EN, Mbatha PM, Macharia J, Abdoel TH, Janszen PV, Pastoor R, Smits HL (2012) Infection of cattle in Kenya with Brucella abortus biovar 3 and Brucella melitensis biovar 1 genotypes. Trop. Anim. Health Prod. 44:17-20.

Mussie H, Tesfu K, Yilkal A (2007a). Seroprevalence study of bovine brucellosis in Bahir Dar Milk shed, Northwestern Amhara Region. Ethiop. Vet. J. 11(1):42-49

Mussie H, Tesfu K, Mulugeta T, Kelay B, Yilkal A, Ahmed A (2007b). Seroprevalence of brucellosis in cattle and occupationally related human in selected sites of Ethiopia. Ethiop. Vet. J. 11(2):49-65.

OIE (2000). Bovine brucellosis: Diagnostic Technique. Manual of Standard for Diagnostic Tests and Vaccines. 4th edition. Paris: Office International des Epizootics pp. 1-37.

Osterman B, Moriyon I (2006) International Committee on Systematics of Prokaryotes; Subcommittee on the taxonomy of Brucella: Minutes of the meeting, 17 September 2003, Pamplona, Spain. Int. J. Syst. Evol. Microbiol. 56:1173-1175.

Pappas G, Papadimitriou P, Akritidis N, Christou L, Tsianos E (2006) The new global map of human brucellosis. Lancet Infect. Dis. 6:9199.

Radostits OM, Gay CC, Blood CD, Hinchcliff KW (2000). Veterinary Medicine, Textbook of the Disease of Cattle, Sheep, Pigs, Goats and Horses. $9^{\text {th }}$ edition. New York: W.B. Saunders Company Ltd, pp. $867-$ 882.

Ragassa G, Mekonnen D, Yamuah L, Tilahun H, Guta T, Gebreyohannes A, Aseffa A, Abdoel TH, Smits HL (2009). Human brucellosis in Traditional pastoral communities in Ethiopia. Int. J. Trop. Med. 4:59-64.

Richard D (1979). Study of the pathology of the Dromedary in Borana Awraja (Ethiopia). Ph. D. Thesis. IEMVT, Maiso-Alfort, France.(English version).

Roberts JS (1971). Veterinary Obstetrics and Genital Diseases. $2^{\text {nd }}$ edition. India: CBS Publisher and Distributors pp. 108-112.

Seifert SH (1996). Tropical Animal Health. $2^{\text {nd }}$ edition. Dordrechet: Kluwer Academic Publishers p. 358.

Sewell MM, Brocklebry DW (1990). Handbook on Animal Diseases in Tropics. $4^{\text {th }}$ edition. London: Bailliere Tindall. p. 41.

Shimeles A (2008). Sheep Brucellosis: Prevalence and its zoonotic impact, MSc thesis, Faculty of Veterinary Medicine, Addis Ababa University, Debre Zeit, Ethiopia.

Skalsky K, Yahav D, Bishara J, Pitlik S, Lelbovici L, Paul M (2008). Treatment of human brucellosis: systematic review and metaanalysis of randomized controlled trials. Br. Med. J. 336:701-704.

Smits HL (2012). Control and prevention of brucellosis in small ruminants: time for action. Vet. Rec. 170:97-98.

Smits HL, Kadri M (2004). Brucellosis. Indian J. Pract. Doctor 3:60-64.

Tariku, S. (1994). The impact of brucellosis on productivity in improved dairy herd of Chaffa State Farm, Ethiopia. Berlin, Frei universitate, Fachburg Veterinaemedizin, Msc Thesis.

Tegegne A, Crawford TW (2000). Draft animal power use in Ethiopia. 
In: Draft animal news, No. 33, Dec. 2000. Center for tropical veterinary Medicine, University Edinburgh.

Tekleye B, Kassali OB, Mugurewa M, Sholtens RG, Tamirat Y (1989). The prevalence of brucellosis in indigenous cattle in Central Ethiopia. Bull. Anim. Health Prod. Afr. 37:97-98.

Teshale S, Muhie Y, Dagne A, Kidanemariam A (2006). Seroprevalence of small ruminant brucellosis in selected districts of Afar and Somali pastoral areas of Eastern Ethiopia: the impact of husbandry practice. Revue de' Elevage et Medicine Veterinaire des Pays Tropicaux 157:557-563.

Teshome H, Molla B, Tibbo M (2003). A seroprevalence study of camel Brucellosis in three camel-rearing regions of Ethiopia. Trop. Anim. Health Prod. 35:381-390.

Thakur SD, Thapliyal DC (2002). Seroprevalence of brucellosis in man. J. Commun. Dis. 34:106-109.

Tolosa T, Ragassa F, Belihy K (2008). Seroprevalence study of bovine brucellosis in extensive management system in selected sites of Jimma Zone, Western Ethiopia. Bull. Anim. Health Prod. Afr. 56:2537.

Tolosa T, Ragassa F, Belihy K, Tizazu G (2007). Brucellosis among patients with fever of unknown origin in Jimma University Hospital South Western Ethiopia. Ethiop. J. Health Sci. 17:59-63.
Walker RL (1999). Brucella. In: Dwight C. Hirsh and Yuang Chung Zee (ED.): Veterinary Microbiology. USA: Blackwell Science Inc. pp. 196203.

Ward D, Jackson R, Karomatullo $H$, Khakimov $T$, Kurbonov $\mathrm{K}$, Amirbekov M, Stack J, El-Idrissi A, Heuer C. (2012). Brucellosis control in Tajikistan using Rev 1 vaccine: Change in seroprevalence in small ruminants from 2004 to 2009. Vet. Rec. 170:100.

WHO (1981). A guide to the diagnosis, treatment and prevention of human brucellosis. VPH/81.31 Rev.1.

WHO (1986). Joint FAO/ WHO Committee on brucellosis. $6^{\text {th }}$ Report. Geneva: WHO. (Technical Report Series. 740).

WHO (1997). Emerging and other communicable disease surveillance and control. The development of new/ improved brucellosis vaccines (Reports of the WHO Meetings, Geneva, December) pp. 1-37.

Yibeltal M (2005). A seroprevalence study of small ruminant brucellosis in selected sites of the Afar and Somali regions, Ethiopia. DVM thesis, Faculty of Veterinary Medicine, Addis Ababa University, Debre Zeit, Ethiopia. 